\title{
Research on the Optimization Measures of China's Civil Disputes Online Resolution Mechanism (ODR) Under the Internet Plus Era Background
}

\author{
Chunlei Sun \\ History of Chinese law, Law Institute, Chinese Academy of Social Sciences, Peking, P. R. China
}

\section{Email address:}

18661901918@163.com

\section{To cite this article:}

Chunlei Sun. Research on the Optimization Measures of China's Civil Disputes Online Resolution Mechanism (ODR) Under the Internet Plus Era Background. International Journal of Law and Society. Vol. 3, No. 4, 2020, pp. 161-167. doi: 10.11648/j.ijls.20200304.12

Received: September 12, 2020; Accepted: October 22, 2020; Published: October 30, 2020

\begin{abstract}
Under the background of the rapid development of Internet information technology, the life style of the people in our country has changed significantly. Most of the information technology has brought good convenience to people's life and work. However, it is important to note that the number of civil disputes is increasing under the background of the "Internet plus" era. This situation also makes the traditional civil dispute resolution mechanism has been in a very significant state of high load, we must carry out the corresponding optimization in the follow-up time. This article combines the current background, puts forward the online dispute resolution mechanism, expounds the establishment and specific application of Online Dispute Resolution mechanism, and analyzes the problems existing in the Online Dispute Settlement Mechanism of China's civil disputes under the background of "Internet plus" era. On the basis of relevant experience in Anglo American law system and continental law system, the paper also proposes three countermeasures to improve the online resolution mechanism of civil disputes in the Internet plus era from the following aspects: continuously improving relevant laws and regulations, improving the level of public cognition, and innovating technology and platform.
\end{abstract}

Keywords: Internet Plus, Civil Disputes, Online Resolution, Settlement Mechanism

\section{Questions Raised}

In the current process of China's social and economic development, the number of civil disputes is increasing. In particular, China is still in the period of social transformation and development, many social contradictions will lead to civil disputes. In this case, it is difficult to achieve good results by relying on the traditional civil dispute resolution mechanism. This is mainly because the cost of traditional mechanisms is higher, and the time of handling disputes is longer. It no longer satisfies the needs of the people in the era of "Internet plus". Therefore, in order to better improve the effectiveness of civil dispute resolution, we can consider the implementation of civil dispute online resolution mechanism. In fact, in 2014, China put forward relevant strategic policies to improve the diversified dispute resolution mechanism. In 2016, China's Supreme Court also issued the opinions on the reform of diversified dispute resolution mechanism ${ }^{1}$. In addition, in the report of the 19th National Congress of the Communist Party of China, China has also continued to emphasize the concept of innovating a diversified dispute resolution mechanism.

One belt, one road, can be found in the current Internet plus era. In the current era of "Internet plus", China has begun to attach importance to the establishment of online dispute settlement mechanism. At the same time, it has gradually guided the establishment of online settlement mechanism through policy content. "Ni Nan" has constructed the online non litigation resolution mechanism of "trade disputes" along the way. [1]. However, it should be noted that the current

\footnotetext{
${ }^{1}$ On June 28, 2016, the Supreme People's Court issued the opinions on further deepening the reform of diversified dispute resolution mechanism by the people's court, which is also an important way to implement the decision of the CPC Central Committee on several major issues of comprehensively promoting the rule of law and the opinions on improving the multi resolution mechanism of contradictions and disputes issued by the general office of the CPC Central Committee and the general office of the State Council.
} 
situation of China's construction in this respect still has very significant deficiencies, compared with developed countries, there is a significant gap. This is mainly because our country has not fully implemented the Internet thinking in dispute settlement, which makes it difficult for the new online dispute resolution system to be fully promoted. Moreover, due to the influence of China's special national conditions, China cannot directly apply the advanced mode of other countries in this respect. All these situations make the online dispute resolution mechanism meet many difficulties in the background of "Internet plus" era in China. We must pay attention to it in the following time and break through all kinds of problems, so as to bring into play the strategic value and significance of this model.

\section{Theoretical Overview of Online Settlement Mechanism of Civil Disputes}

The online settlement mechanism of civil disputes is actually an imported product. In order to carry out the system comprehensively in China, we should strengthen theoretical analysis and exploration, and make clear the agreement between the system and the actual situation and social environment of our country. First, the analysis of legal theory. Online Dispute Resolution mechanism has not been confirmed in the current legal level of China, but the legal effects of electronic evidence are regulated in various laws, including civil procedure law, which provides a better legal theoretical guarantee for the full implementation of Online Dispute Resolution mechanism. In addition, in the e-commerce law, which was revised in 2018 , online dispute resolution mechanism has been introduced into the field of e-commerce. All of these contents can provide a good legal support for the application of online settlement mechanism of civil disputes. Second, the basic theory of civil disputes. This theory is the basic reference theory of civil dispute handling, which can provide legal support for both parties to settle disputes legally [2]. In the era of "Internet plus", the online dispute settlement mechanism needs to be fully implemented in order to ensure that online dispute system can achieve better results.

\section{The Status Quo of Online Dispute Resolution Mechanism in China Under the Background of "Internet Plus" Era}

\subsection{The Establishment of Online Dispute Resolution Mechanism in China Under the Background of "Internet Plus" Era}

Under the background of the "Internet plus" era, the establishment of Online Dispute Settlement Mechanism in China can transform the legal application from the previous internal operation to the legal service. The internal operation mode mainly refers to the integration of various Internet technologies into the original civil dispute settlement system, which can significantly improve the efficiency of dispute resolution and realize the modernization and systematization of dispute resolution. For example, in the process of civil litigation, electronic transmission can be used for the transmission of documents, which makes the whole litigation mode faster and more efficient [3] The legal service refers to the formation of a new type of dispute resolution mode, which relies on the subject of civil disputes and links the Internet technology with the innovation of dispute resolution mode. In fact, many e-commerce platforms in China have begun to build such legal services when they are developing, and gradually improve their own internal complaint mechanism, so that both parties can solve all kinds of disputes online while enjoying e-commerce services [4] For example, the idle fish court has been set up in the idle fish app, which is a new way to solve user disputes and protect users' rights. The whole platform uses Internet technology and platform information resources, and adds big data, artificial intelligence and other modes. Most disputes can be handled within 12 hours. If it is not completed within 12 hours, it will be followed up by manual customer service. In the current process of social development in our country, the online settlement mechanism of civil disputes has been well constructed in the field of industry in China. Network mediation, network arbitration, network litigation and other modes have begun to get a better understanding of the public. This also shows that the online dispute resolution mechanism has become more common in the era of "Internet plus", and Internet technology has provided more paths and solutions for civil dispute resolution. However, combined with the overall development of the current situation, the establishment of China's civil dispute online settlement mechanism is still in the process of continuous exploration, which needs to be comprehensively discussed in the follow-up time.

\subsection{Breakthrough of Online Dispute Resolution Mechanism in China Under the Background of "Internet Plus" Era}

At the beginning of the 21 st century, the online settlement mechanism of civil disputes was introduced into China from abroad, especially the establishment of domain name dispute resolution center, which also directly marks the establishment of Online Dispute Resolution Mechanism in China. However, due to the lack of relevant theoretical research in China, the development of Online Dispute Resolution mechanism has been very slow. Until the "Internet plus" strategy was launched, China's online dispute resolution mechanism began to usher in a better development opportunity and began to enter a period of rapid development. Especially in 2016, China's Supreme People's Court issued the "notice on the pilot work of online mediation platform construction in some courts" and other documents, which directly promoted the construction effect of online settlement mechanism and realized the breakthrough of this mechanism in China's social 
environment $^{2}$. In the current judicial practice, many regions in China have begun to actively respond to such policies and accelerate the construction of Online Dispute Resolution platform. These situations make online dispute resolution mechanism in China's social environment has been a more significant breakthrough, began to gradually play the strategic role of this technology. Therefore, in the following development period, China should attach more importance to the comprehensive implementation of this system in the context of the "Internet plus" era, and ensure that this system can play a better strategic role in the complex social environment and the Internet economic system in China.

\subsection{Application of Online Dispute Resolution Mechanism in China Under the Background of "Internet Plus" Era}

Under the background of the "Internet plus" era, the Online Dispute Settlement Mechanism of civil disputes has been applied in a more comprehensive way, making the system play a better role.

First, online mediation platform. In December 2017, China established the mediation center of the E-Commerce Association, which is also the largest online mediation platform in China, which is mainly used to solve disputes in the Internet economy, such as network infringement disputes, e-commerce transaction disputes and other civil disputes [5]. The establishment of this platform enables the parties to release their opinions through the Internet platform, and the time required for the whole dispute settlement is relatively small. When dealing with specific disputes, the parties can register their accounts through this platform and choose how to settle disputes. When receiving the application from the parties concerned, the platform will have a detailed understanding through e-mail or telephone, and make clear the details of the parties' appeal affairs, and make clear whether this matter is within the scope of the platform for handling disputes. After meeting the mediation scope of the platform, the platform will accept these services and enter the subsequent mediation process. At the end of mediation, the platform will generate a mediation agreement, which will take effect after being signed by both parties. Every dispute case accepted by the platform will be filed and published in the website platform for reference by others.

Second, online arbitration platform. This paper mainly takes the CIETAC domain name dispute resolution center established in 2000 as an example for a comprehensive analysis. This platform has fully implemented the online arbitration module. Since the establishment of the platform,

\footnotetext{
${ }^{2}$ On February 16, the Supreme People's court held the launching ceremony of the pilot online mediation platform in Ma'anshan, Anhui Province. The notice on carrying out the pilot work of online mediation platform construction in some courts (hereinafter referred to as the notice) was read out. Six Higher People's courts in Beijing, Hebei, Shanghai, Zhejiang, Anhui and Sichuan and Shanghai maritime court were identified as pilot courts. The notice made it clear that the pilot high court should take the lead in establishing a unified online mediation platform at the provincial level, establish a full coverage of dispute acceptance, diversion, mediation, feedback and other processes, and promote the resolution of disputes in accordance with the law, justice, convenience and efficiency.
}

the platform has accepted more than 30000 arbitration cases. At the same time, the current arbitration rules of the platform are similar to international standards, and online mediation mode is also integrated into the implementation of online arbitration, which makes the arbitration of the platform more flexible. In the specific operation of the platform, both parties can carry out relevant activities on the network. At the same time, the online hearing time is relatively short, which can be completed in one or two days, which has a high effect and low cost level. In 2019, the platform also opened the dual system operation of PC terminal and wechat mobile terminal, so that the parties can conduct online arbitration activities more conveniently through terminals such as computers and smart phones.

Third, online court platform. In 2016, Hangzhou established the Internet court, which is also an important symbol of the establishment and operation of China's online court system. From its establishment to the end of 2019, Hangzhou Internet court has tried 14719 cases. At the same time, the average trial time of each case is 28 minutes. The online judgment rate reaches $60 \%$, and the first instance decision rate reaches $99.06 \%$. Combined with the operation status of Hangzhou Internet court, it mainly solves various disputes such as Internet shopping, Internet copyright and Internet domain name disputes. In the use of this platform, the parties can use the real name registration of personal information through the official website of the platform, so as to carry out relevant operations according to the platform guidelines, and finally resolve disputes through online means.

In view of the above contents, the online settlement mechanism of civil disputes has begun to be applied in China, and has achieved good results. However, from a macro point of view, this mechanism has not been widely used, and compared with the traditional dispute resolution mechanism, there are still many deficiencies in the occupancy rate. This is mainly because in the current "Internet plus" era, the implementation of Online Dispute Resolution Mechanism in China still has a significant obstacle. It needs to be fully concerned in the following time and can provide corresponding solutions. The following are also based on this point, and explore the problems and specific countermeasures of Online Dispute Resolution Mechanism in China under the background of "Internet plus".

Fourth, the problems of Online Dispute Settlement Mechanism in China under the background of "Internet plus" era.

\subsubsection{The Relevant Laws and Regulations Are Not Perfect}

At present, in the development process of ODR service, there are still some obvious imperfections in relevant laws and regulations, which are mainly reflected in two aspects. First, substantial obstacles. At present, there is no legal system to support ODR service in China. At present, the "Internet +ADR" model referred to in China only provides the path of dispute resolution, and cannot provide substantive legal support. At present, China's "Civil Procedure Law" and other laws provide relatively limited entity support, which needs to 
be improved in the follow-up time. For example, when using ODR services, electronic data is often used as evidence support. However, in addition to electronic evidence, other electronic data are still in a blank state in the current legal system, which may lead to different judgments in the same case due to the lack of these legal rules [6]. Second, procedural obstacles. In the process of implementing ODR service, it is likely to encounter procedural obstacles, among which the prominent ones are jurisdictional and executive barriers. Among them, the jurisdiction obstacle mainly refers to that the Internet online dispute resolution has broken the regional limit, which is likely to cause judicial confusion in the court system, and the courts in different regions vie for jurisdiction or shirk responsibility each other. The implementation obstacle refers to that the dispute resolution opinions and results generated by ODR service cannot be fully implemented in the real environment, and the execution ability is insufficient. This situation also makes ODR service content become empty talk and lose its original effect.

\subsubsection{The Cognitive Level of the Public Is Not Enough}

Under the background of the "Internet plus" era, the public's cognition level of civil dispute resolution still has a significant deficiency. Although in the process of development in recent years, China has been implementing a diversified dispute resolution system, but the public in our country do not trust other dispute resolution methods except court proceedings. Therefore, when encountering civil disputes, many people will not choose to use online dispute resolution mechanism, but will choose to use court proceedings to protect their rights [7]. Besides, there is still a significant lack of cognition on the Internet plus concept at the social level in China, which makes the data of ODR service platform relatively closed. Combined with the current situation of the Internet dispute resolution platform in China, most of the platforms have established their own special databases. At the same time, all kinds of data information in the database are for internal use only, and rarely share and exchange data with the outside world. This situation is not conducive to the long-term development of ODR services.

\subsubsection{Lack of Platform and Technology}

Combined with the current development of ODR services in China, there are still significant deficiencies in platform construction and technology use. First, the identity authentication technology of the platform has problems. At present, many ODR service platforms in China usually open anonymous dispute services for the reason of protecting the privacy of the parties. Even if the platform requires real name authentication, there are still many parties involved in online dispute resolution through false information. This kind of false identity has brought a very significant negative impact on the subsequent operation of ODR services, and it is necessary to make targeted adjustments in the follow-up time [8]. Second, confidentiality technology. Civil disputes in the Internet environment to deal with, but also make a lot of information will be placed in the Internet environment. This situation also makes part of the party's key information may be threatened by malicious attacks and other situations, resulting in information disclosure or tampering, and eventually the disclosure of the party's privacy or business secrets. Third, the platform has single function. At present, many ODR service related platforms in China have single function. When the platform does not have the function of online judicial confirmation, the parties need to go to the court in person to confirm the online mediation agreement. These single function platforms will significantly limit the development of ODR services, and it is necessary to make targeted adjustments and improvements in the follow-up period.

\subsubsection{The Experience of Online Dispute Resolution Mechanism in China Under the Background of "Internet Plus" Era}

(1) Common law system

In the course of its development for many years, the UK has always attached great importance to the online settlement of civil disputes (ODR), which is also regarded as an important goal of its own judicial reform. In view of the current actual development, the British government and social organizations have invested a lot of money in the construction and maintenance of Online Dispute Resolution platform. For the UK, ODR mode is not only an important means to improve the efficiency of its own civil dispute resolution, but also the core point to realize the innovation and reform of its own judicial system. At present, ODR services in the UK can be divided into three types: small amount telephone arbitration mediation, telephone Hearing of small cases and small amount of online debt collection service. In addition, on the basis of the implementation of ODR services, the UK has also built an online court system. This online court system has strong execution and judgment ability, and the cost is significantly lower than the traditional court.

The application of ODR services in the United States is significantly higher than that in other countries, which is mainly due to the early development of Internet technology in the United States, and the local ADR mechanism is relatively perfect. Combined with the actual situation in the United States, the practical application of ODR service is mainly concentrated in three parts. First, online negotiation and mediation. There are many online negotiation and regulation platforms in the United States, among which square trade is the most famous platform. This platform can realize the independent review of both parties in the platform, avoid all kinds of legal risks in the transaction process, and better solve legal disputes, and second, online arbitration. Online arbitration is also one of the most popular ODR services in the United States. At present, the cases accepted by the American Arbitration Association are also the first in the world. At the same time, many foreign-related disputes have been handled. The online arbitration function of American Arbitration Association is very complete. At the same time, it also builds a network file system, which can make arbitrators, parties and other subjects better understand the situation of the case. Third, online courts. The first Internet court, Michigan Internet court, was established in 2003 in the United States. The court has 
fully implemented the relevant contents of ODR service, and launched case trial activities through various feasible ways such as email, online filing, video conference, etc., which significantly improved the efficiency of dispute handling.

(2) Civil law system

In the civil law countries, the research and comprehensive application of ODR services are mainly concentrated in European Union countries, such as France, Germany and so on. In these countries, there has been a relatively unified understanding of ODR services, and at the same time began to establish ODR platform. In these countries, consumers can log in to the ODR platform to fill in the application form for dispute resolution. The platform will be sent to the respondent after receiving the application. According to the operation status of ODR platforms in France, Germany and other EU countries, the ODR platform itself has not directly resolved disputes. Both parties mainly choose one institution from the ADR institutions list provided by the ODR platform as the dispute settlement agency. After settling the disputes, ADR institutions should also feed back the final results to the ODR platform.

(3) Experience for reference

Compared with the domestic, the research on Online Dispute Resolution in foreign countries is relatively early, and also formed a relatively rich research results, here is also a comprehensive elaboration and analysis.

First, improve the trust of online dispute resolution. In foreign developed countries, the main reason why ODR service can be well implemented is that the public trust this service mode. At present, many people in our country don't know about ODR service, which makes it difficult for people to implement and develop ODR service in China.

Second, enhance the execution of the dispute resolution results. In the United States, the United Kingdom and other countries, after the online dispute resolution system finally produces the results and opinions, the law enforcement is generally relatively high, which can better reflect the effect of online dispute resolution system. However, many ODR services in our country, the final dispute settlement results are difficult to be fully implemented in the real environment, which makes the dispute settlement structure has no good executive power. This situation is also an important factor leading to the failure of ODR service in China.

Third, it is necessary to integrate information technology. Both the common law system and the civil law system start to use all kinds of information technology flexibly in the implementation of ODR service, so that all kinds of information of online settlement of civil disputes can get better circulation. At present, there are still many deficiencies in the level of informatization construction in China, which need to be improved and adjusted in the follow-up period.

\subsubsection{The Improvement Measures of Online Dispute Settlement Mechanism in China Under the Background of "Internet Plus" Era}

(1) Constantly improve relevant laws and regulations

i. Gradually adjust the content of legislation
In view of the fact that there is no special legislation on ODR service in China, it is better to establish a special legal system in the follow-up period to provide better legal support for the normal operation of ODR service [9]. In terms of specific legislation, we can consider starting from four aspects. First, the definition, type and effectiveness of ODR services should be clearly defined through legal source documents, so as to truly clarify the legitimacy and details of each part. Second, the current "Civil Procedure Law" and other legal documents should be revised and adjusted to solve the legal confusion caused by multiple laws supporting ODR services. Third, optimize the preset procedure rules and Industry Association standards in the ODR platform, clarify the legal support and dependence of each business link in the platform, and ensure that every activity in the ODR platform can get better legal support. Fourth, other relief channels must be set up in all ODR platforms. These other channels can choose other processing channels and methods when the parties do not agree with the solution provided by the ODR platform.

ii. Improve the legal jurisdiction system

In the full implementation of ODR services, we should also solve the problem of legal jurisdiction. This also needs to be based on the legal level to clarify the legitimacy of ODR services. On the one hand, China can give ODR service a reasonable identity through legislation. But this way needs to be planned and designed in long-term observation and practice, which is difficult to achieve in a short time. On the other hand, China can actively learn from the ODR jurisdiction system implemented in foreign countries, and actively analyze with the current legal system of our country. If we can find common ground, we can choose to apply [10]. This way can avoid the tedious legislation and supplement the deficiency of the legal jurisdiction system. But in the long run, we still need to solve the problem of legal jurisdiction through legislation.

iii. Determine the law enforcement mechanism

For the implementation of online dispute settlement results, we should not only rely on the consciousness of the parties, but also establish the corresponding system content to restrict the implementation. In this process, other regions of China can consider actively learning from Guangxi Beihai arbitration mode. That is, before applying for online arbitration service, the parties need to pay the execution advance payment. If the parties refuse to execute the dispute through the online arbitration service, the advance payment for execution may be considered to be withheld. When the parties concerned consciously implement the dispute settlement results, the advance payment will be returned from the original channel. This kind of prepayment mode can avoid some parties abusing their power to damage the interests of others, and can also significantly improve the execution efficiency of dispute resolution results.

(2) Improve the cognitive level of the public

i. Change the concept of the public

In the follow-up development process, our country should actively change the concept of the public, change the thinking of the public, so that the public can break through the traditional legal system and court litigation to solve disputes. 
In fact, in our party's conference documents, the diversified dispute resolution path has been constantly mentioned, at the same time, it has been better applied in many areas of our country. Therefore, in the follow-up period, China should also be able to fully integrate into the diversified dispute settlement mechanism in the daily legal popularization activities, and gradually change the concept of the public.

ii. Improve public awareness

When we continue to implement the diversified dispute resolution mechanism system, we should gradually form an overall pattern of Party and government leadership, government led, social participation, pluralism and legal protection. This also requires that our country can continuously improve the cognitive level of the public and provide better social environment support for the comprehensive implementation of ODR services. In this process, China should make clear the Development Essentials of ODR service, that is to ensure social stability and harmony. Therefore, when the government takes the lead to establish various ODR platforms, we should highlight the public welfare and service of the platform, so that the public can actively participate in it, and ultimately improve the cognitive level of the public in practice.

iii. Accelerate the development of social education

In the follow-up period, China should also strengthen the social education activities of ODR service. On the one hand, China can introduce ODR service related cases into the school education system, improve the depth of our students' understanding of ODR services, and ultimately change the understanding level of the next generation of groups for ODR services. On the other hand, China should also actively publicize ODR services to the public through various feasible ways, such as offline public welfare announcement, online wechat microblog publicity, etc., which can ultimately improve the public's cognitive level of ord service, which is conducive to the comprehensive implementation of ODR service in China's social environment.

(3) Innovation of technology and platform

i. Build online network platform

In the current era of "Internet plus", ODR online platform has been able to play a better strategic significance. Therefore, in the follow-up development process, China should also be able to actively integrate resources and build a unified platform. In this process, China can consider improving the cohesion of each platform to avoid the situation of each platform fighting its own way.

ii. Constantly innovate technical means

In the development process of Internet online platform, the platform itself should also actively carry out technological innovation. On the one hand, China should strengthen the technical exchange between itself and developed countries, and at the same time, invest certain funds in technological innovation to improve the comprehensive quality level of technical personnel [11]. On the other hand, China should also gradually simplify the business process of the ODR platform, and actively use data encryption technology and other technologies to improve the security of its own platform operation, so as to provide more abundant ODR service guarantee [12].

iii. Build and improve the security system

In order to ensure that ODR services can achieve good results, China should also be able to build corresponding security system in the follow-up period. In this process, China's government departments should provide better policy support for the comprehensive implementation and development of ODR services, and at the same time, we should constantly enrich the guarantee system of ODR services combined with practical activities, and promote the harmonious and long-term development of ODR platform.

\section{Conclusion}

On the whole, under the background of the "Internet plus" era, the online dispute resolution mechanism can be applied well, and it has also achieved some results. However, it should be noted that there is still a significant gap between China's online solution mechanism and foreign developed countries. In the follow-up development process, China should actively learn from the advanced experience of foreign developed countries in this respect, and at the same time, we should make targeted adjustments according to our special national conditions, so as to make the legal support system more perfect [13]. In this, our country should also continue to improve the public's awareness of ODR services, and at the same time, enhance the public's understanding of this content through online + offline ways, so as to provide a good foundation for the comprehensive implementation of ODR services. In addition, our country should strengthen the research on ODR network online platform in the follow-up period, and at the same time, we should use various new technology flexibly to ensure that these online platforms can play a better role [14]. In this way, ODR services can be implemented in China in the era of "Internet plus" and give full play to corresponding strategic role.

\section{References}

[1] $\mathrm{Wu}$ Xinjie. How does the ODR Work in China? [J]. humanities magazine, 2017 (01): 37-43.

[2] Lu tarang. Basic theory of civil litigation [M]. University of political and legal press, 2003.

[3] Liu Qingyang, Jin Peng. The construction of online non litigation dispute resolution mechanism in civil and commercial affairs -- Taking the trade between China and Russia as an example [J]. Jianghan forum, 2018 (10): 128-131.

[4] Xu Fang, Liang Jinlin. Discussion on innovation of consumer dispute resolution mechanism of $\mathrm{B} 2 \mathrm{C}$ cross border e-commerce [J]. Business economics research, 2018, 760 (21): 129-132.

[5] Li Yan, Zhang Tian, Lu Shanshan. Online shopping disputes and their settlement mechanism in China [J]. Cooperative economy and technology, 2019 (07): 186-187. 
[6] He Yuyan. Research on alternative dispute resolution mechanism for recourse to overseas Lost Archives: taking wipo-icom mediation rules as an example [J]. Zhejiang archives, 2019, 454 (02): 24-26.

[7] Zheng Shibao. On the improvement of Online Dispute Resolution Mechanism in China [J]. Journal of Graduate School of Chinese Academy of Social Sciences, 2017 (04): 128-138.

[8] $\mathrm{Hu}$ Xiaoxia. The Realistic Dilemma and future way out of China's online dispute resolution mechanism [J]. Law forum, 2017 (03): 97-105.

[9] Zhu Xinyu, Lu Zhengmin. A new way to resolve P2P online loan disputes -- from the perspective of online arbitration [J]. Chinese certified public accountant, 2017 (4): 158-169.

[10] Yuan Chengli. Construction of online non litigation dispute resolution mechanism between China and Russia [J]. Academic exchange, 2018 (12): 190-190.

[11] Ren zhuolan, he pengpeng. A new exploration on the approach of consumer dispute arbitration settlement mechanism [J]. Inner Mongolia Social Sciences, 2015 (15): 78-99.

[12] Han Bo. Urbanization disorder, new citizens and the convenient upgrading of civil dispute resolution mechanism [J]. Journal of China University of political science and law, 2016 (02): $15-30+158$.
[13] Ni Nan. One belt, one road trade dispute resolution mechanism on line non litigation settlement [J]. humanities journal, 2017 (01): $37-43$

[14] Han Ping, Lang Manman. Problems and Countermeasures of Online Dispute Resolution Mechanism in China, [J]. China market, 2014 (02): 12-18 + 130 .

\section{Biography}

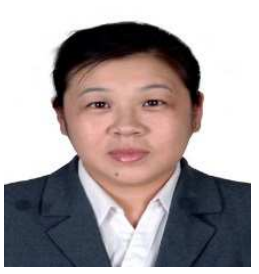

Sun Chunlei (1980 -), female, Qingdao, Shandong Province, Ph. D. candidate, Law Institute, Chinese Academy of Social Sciences, research interests: legal anthropology, legal sociology. Sun Chunlei is the tutor of the master of law of the people's Public Security University of China, and the Chinese youth entrepreneurship tutor of the Central Committee of the Communist Youth League. Sun Chunlei's knowledge structure spanning three disciplines: law -management- economic, She studied in Switzerland and U.S.A Sun Chunlei has published more than 10 papers in legal research, Guizhou ethnic studies, human rights studies, etc. She alsohas rich practical experience. 